\title{
A new tumor-specific variant of GRP78 as target for antibody-based therapy
}

\author{
Nicole Rauschert ${ }^{1}$, Stephanie Brändlein ${ }^{1}$, Elisabeth Holzinger ${ }^{1}$, Frank Hensel $^{2}$, Hans-Konrad Müller-Hermelink ${ }^{1}$ \\ and $\mathrm{H}$ Peter Vollmers ${ }^{1}$
}

The chaperone GRP78 is a member of the heat-shock protein 70 (HSP70) family and is responsible for cellular homeostasis by preventing stress-induced apoptosis. GRP78 is expressed in all cells of the body. In malignant cells, which are permanently exposed to environmental stress, GRP78 is overexpressed and increased levels can be found in the cytoplasm and on the cell membrane. Thus, GRP78 promotes tumor proliferation, survival, metastases and resistance to a wide variety of therapies. Like other tumor-specific membrane molecules, GRP78 can also be present on cancer cells in a variant form. This modification qualifies it as a target for immune surveillance and antibody responses. The fully human monoclonal IgM antibody, SAM-6, was isolated from a gastric cancer patient and it binds to a new variant of GRP78 with a molecular weight of $82 \mathrm{kDa}$. The epitope is an O-linked carbohydrate moiety and is specific for malignant cells. These data show that cancer-specific modifications of cell-surface protection molecules are (a) subject of an immune response and (b) ideal targets for new therapeutical approaches. Laboratory Investigation (2008) 88, 375-386; doi:10.1038/labinvest.2008.2; published online 11 February 2008

KEYWORDS: GRP78; heat-shock protein; human monoclonal IgM; lipotoxicity; natural immunity; post-transcriptional modification

GRP78 and other glucose-regulated proteins (GRPs) are endoplasmic reticulum (ER) chaperones that belong to the heat-shock protein (HSP) family. HSPs are present in all cells of an organism, ${ }^{1}$ and play important roles in maintaining cellular homeostasis. ${ }^{2,3}$ Stressful events, induced by environmental, pathological and physiological stimuli, lead to an increased intracellular synthesis of HSPs. ${ }^{4}$ At high levels, the chaperones protect the cell against ER stress-induced apoptosis and maintain cell viability after exposure to stressinducing conditions. ${ }^{5}$ The result is a complex network of regulators and protective mechanism, which help the cell to respond to stress stimuli ${ }^{2}$ and to prevent cellular degradation processes, induced by apoptosis and autophagocytosis. ${ }^{6}$

HSPs are normally cytoplasmic proteins, but under diverse pathological conditions they are overexpressed and found on the surface of cells, ${ }^{7}$ where they may serve as cell-surfacesignaling receptors. ${ }^{8,9}$ Elevated levels of GRP78 were found on a variety of human cancers, including breast cancer, lung cancer, liver and prostate cancer. They correlate with tumor progression, ${ }^{10}$ metastasis ${ }^{11}$ and drug resistance to a variety of therapies. ${ }^{12-16}$ The protection of tumor cells from chemotherapeutic agents induced by GRP78 is associated with bad prognosis, as recently reported in case of breast cancer, ${ }^{15,17}$ prostate cancer ${ }^{5,18}$ and gastric cancer patients. ${ }^{11}$

Although GRP78 is overexpressed on the membrane of malignant cells, the surface localization of GRP78 is also reported on other cells, such as proliferating endothelial and monocytic cells. ${ }^{19,20}$ In this case surface-located GRP78 plays protective roles in the progression of atherothrombosis and shows inhibitory effects on progression of cardiovascular diseases. ${ }^{7,20}$ The problem of possible adverse effects limits the use of GRP78 as target for cancer treatments. However, tumor cells express two different forms of GRP78 on their surface. GRP78, like many other glycoproteins, is present on the surface of cancer cells, ${ }^{21}$ modified by post-transcriptional modification of its carbohydrates. These modifications are in contrast to the 'wild type' unequivocally tumor-specific and are in addition targets for immune-surveillance processes. $^{22,23}$

The human monoclonal IgM antibody SAM-6, isolated from a stomach cancer patient, binds to a posttranscriptionally modified isoform of the $78-\mathrm{kDa}$ GRP with a molecular weight of $82 \mathrm{kDa}$, named GRP78 ${ }^{\mathrm{SAM}-6}$. The epitope is an $\mathrm{O}$-linked carbohydrate moiety. In a previous

\footnotetext{
${ }^{1}$ Institute of Pathology, University of Würzburg, Würzburg, Germany and ${ }^{2}$ Patrys GmbH, Friedrich-Bergius-Ring 15, Würzburg, Germany Correspondence: Professor Dr HP Vollmers, MD, Institut für Pathologie, Universität Würzburg, Josef-Schneider Strasse 2, Würzburg D-97080, Germany. E-mail: path027@mail.uni-wuerzburg.de
} 
study, we demonstrated that SAM-6 is internalized via endocytosis and is finally responsible for a lethal accumulation of oxidized lipoproteins followed by apoptosis. ${ }^{24,25}$

Modified protection molecules like GRP78 ${ }^{\mathrm{SAM}-6}$ are excellent targets for specific antibodies, which not only might neutralize the protective effect of tumor cells and disable mechanisms of drug resistance, but also, as shown in this paper, directly kill the cancer cells by inducing apoptosis.

\section{MATERIALS AND METHODS Cell Culture}

SAM-6-producing hybridoma cells, human epithelial carcinoma cell lines BXPC-3 and 23132/87 were cultured as described previously. ${ }^{24,25}$

\section{Purification of SAM-6 Antibody}

Cell-culture supernatant was purified using cation-exchange chromatography ${\left(\text { HiTrap }^{\text {TM }}\right.}^{\text {SP }}$ FF column, Amersham Bioscience, Freiburg, Germany) as described elsewhere. ${ }^{25}$ Purity of the antibody was determined by sodium dodecylsulfate (SDS)-PAGE and activity was confirmed by immunohistochemistry and functional assays.

\section{Immunohistochemical Staining of Paraffin Sections}

Immunohistochemistry with SAM-6 antibody or control antibodies on human tissue was performed as described elsewhere. $^{24}$

\section{Preparation of Tumor Cell Membrane Extracts and Western Blotting}

Membrane proteins were isolated from the human stomach carcinoma cell line 23132/87 and the pancreas carcinoma cell line BXPC-3 using the ProteoExtract ${ }^{\mathrm{TM}}$ Native Membrane Protein Extraction kit (M-PEK; Calbiochem, Darmstadt, Germany). The whole procedure of the extraction of integral and membrane-associated proteins was performed according to the manufacturer's protocol. This method guarantees sufficient enrichment of membrane proteins and requires no further sub-cellular fractionation.

Subsequently, the tumor cell membrane extract was examined by SDS-PAGE and western blotting as described elsewhere. ${ }^{24}$ In short, blocked nitrocellulose membranes were incubated with $25 \mu \mathrm{g} / \mathrm{ml}$ of human IgM antibody SAM-6, or with unrelated control (ChromPure human IgM; Dianova, Hamburg, Germany) at the same concentration. The secondary antibody (peroxidase-coupled rabbit anti-human IgM antibody 1:1.000; Dianova) was detected with the SuperSignal ${ }^{\circledR}$ West Pico Chemiluminescent Substrate from Pierce (Perbio Science Deutschland GmbH, Bonn, Germany).

\section{Purification of SAM-6 Antigen}

For isolation of the SAM-6 antigen, crude membrane protein extract of cell line 23132/87 was injected onto an equilibrated Superdex 200 column (XK16/60; Amersham Biosciences, Uppsala, Sweden) and eluted with buffer A
(100 mM Tris/HCl, pH 7.5, $40 \mathrm{mM} \mathrm{NaCl,} 2 \mathrm{mM}$ EDTA, $1 \%$ Triton X-100) at a flow rate of $2 \mathrm{ml} / \mathrm{min}$ using fast protein liquid chromatography (Amersham Pharmacia Biotech, Freiburg, Germany). Fractions of $2 \mathrm{ml}$ each were collected and monitored at $280 \mathrm{~nm}$. After concentrating the eluate by acetone precipitation, the protein pellet was dissolved and examined by SDS-PAGE and western blot analysis for reaction with SAM-6 antibody. In a further purification step, the partially purified sample was applied to an equilibrated anion-exchange column (HiTrap ${ }^{\mathrm{TM}}$ Sepharose Q XL; Amersham Biosciences, Uppsala, Sweden). Unbound components were eluted with buffer $\mathrm{A}$, whereas bound protein was released by increasing salt concentration via step gradient using buffer $\mathrm{B}$ (100 mM Tris/HCl, pH 7.5, $1 \mathrm{M} \mathrm{NaCl}, 2 \mathrm{mM}$ EDTA, $1 \%$ Triton X-100). SAM-6 antigen was eluted at $300 \mathrm{mM}$ concentration of $\mathrm{NaCl}$. Again, a flow rate of $2 \mathrm{ml} / \mathrm{min}$ was used, and fractions of $2 \mathrm{ml}$ were collected and monitored at $280 \mathrm{~nm}$. After acetone precipitation, electrophoretic separation and western blotting followed. SAM-6-positive bands were excised from the Coomassie-stained gel and sequenced.

\section{Protein Identification by Peptide Mass Mapping}

The whole procedure of protein sequencing was performed by TopLab (Martinsried, Germany). After one-dimensional SDS-PAGE and Coomassie staining, a protein band with an estimated molecular mass of $82 \mathrm{kDa}$ was excised. After reduction and alkylation with iodoacetamide, the band was in-gel digested with trypsin. The pool of tryptic peptides was desalted with ZipTip C18 and analyzed by matrix-assisted laser desorption ionization (MALDI) mass spectrometry (Voyager-DE STR; Applied Biosystems, CA, USA) and subsequent databank research (Profound and Mascot $v s$ NCBI). Hits for the best matching protein candidates (probability of 1.00) were compared using the Basic Local Alignment Search Tool (BLAST; www.ncbi.nlm.nih.gov/BLAST).

\section{Transfection Experiments of GRP78 Target Molecule with Small Interfering RNA}

Cell line BXPC-3 was used for SAM-6 antigen binding studies after transfection with small interfering RNA (siRNA). SiGENOME SMARTpool reagent targeting human HSPA5 (heat shock $70-\mathrm{kDa}$ protein 5) RNA, pre-designed and validated siRNA for silencing the target molecule GRP78, was purchased from Dharmacon (Lafayette, CO, USA). The oligonucleotides used to suppress gene expression of HSPA5 were as follows: (a) HSPA5 siRNA no. 1 targeting nucleotides 1094-1112 (CGACUCGAAUUCCAAAGAUdTdT), (b) HSPA5 siRNA no. 2 targeting nucleotides 1366-1384 (GAUAAUCAACCAACUGUUAdTdT), (c) HSPA5 siRNA no. 3 targeting nucleotides 1615-1633 (GAAAGGAUGGUUAA UGAUGdTdT) and (d) HSPA5 siRNA no. 4 targeting nucleotides 1821-1839 (CCACCAAGAUGCUGACAUUdTdT). A Silencer ${ }^{\mathrm{TM}}$ Negative Control, as control for nonspecific effects on gene expression caused by siRNA introduction, was purchased from Ambion (Cambridge, UK) and 
comprised a 19-bp scrambled sequence with no significant homology to known gene sequences from mouse, rat or human. Mock-transfected (without siRNA) and untreated cells (grown in complete RPMI 1640, not transfected) served as further controls. Additionally, Silencer ${ }^{\mathrm{TM}} \mathrm{Cy}^{\mathrm{TM}} 3$-labeled siRNA (Ambion, Cambridge, UK) was transfected and verified by confocal microscopy to control delivery of siRNA into the cells. siRNAs were transfected using siLentFect ${ }^{\mathrm{TM}}$ Lipid (BioRad Laboratories, CA, USA).

The day before transfection, 24-well cell culture plates were seeded with $1 \times 10^{4}$ cells/well in complete growth medium (50\% confluent the following day). Plates were incubated overnight at $37^{\circ} \mathrm{C}$ under $7 \% \mathrm{CO}_{2}$. Before transfection, the medium was carefully replaced by adding $0.4 \mathrm{ml}$ of fresh complete medium per well. For each well, $100 \mu \mathrm{l}$ of transfection mixture (containing $49 \mu \mathrm{l}$ serum-free OptiMEM (Invitrogen, Karlsruhe, Germany), $1 \mu \mathrm{l}$ of siLentFect Lipid and $50 \mu \mathrm{l}$ of siRNA dilution) was prepared and added to the cells. Cells were transfected with a final concentration of $25 \mathrm{nM}$ of each siRNA. Transfected cells were incubated over a period of 1 and 3 days at $37^{\circ} \mathrm{C}$ in an atmosphere of $7 \% \mathrm{CO}_{2}$. Knockdown of the target molecule, GRP78, after the indicated time period was monitored by western blot and FACS analysis.

\section{Detection of GRP78 Protein Knockdown by FACS Analysis}

Transfected cells were harvested after 1 and 3 days by gentle detachment with trypsin/EDTA (PAA, Vienna, Austria). A total of $2 \times 10^{5}$ cells were incubated on ice with SAM-6 antibody $(100 \mu \mathrm{g} / \mathrm{ml})$, anti-GRP78 antibody $(100 \mu \mathrm{g} / \mathrm{ml}$; clone ET-21; Sigma, Taufkirchen, Germany) or anti-CD55 antibody (1:50; clone 143-30; DPC Biermann, Bad Naunheim, Germany) for $30 \mathrm{~min}$. Unrelated human IgM (Chrompure IgM; Dianova) and rabbit/mouse IgG (Sigma) served as negative controls. Incubation with FITC-labeled secondary antibodies (rabbit anti-human IgM antibody; Dako, Hamburg, Germany; goat anti-rabbit IgG or goat anti-mouse IgG; both from Acris, Hiddenhausen, Germany) for $15 \mathrm{~min}$ followed. Cells were analyzed by flow cytometry (FACScan; Becton Dickinson, San Jose, CA, USA) using WinMDI software.

\section{Detection of GRP78 Protein Knockdown by Western Blot Analysis}

Transfected cells were harvested after 3 days by gentle detachment with trypsin/EDTA (PAA) and membrane proteins were isolated using the M-PEK; Calbiochem) according to the manufacturer's protocol. Tumor cell-membrane extracts were examined for binding of SAM- 6 antibody by SDS-PAGE and western blotting as described before. ${ }^{24}$ Additionally, suppression of the target protein, GRP78, was affirmed by western blotting with anti-GRP78. In short, blocked nitrocellulose membranes were incubated with $25 \mu \mathrm{g} / \mathrm{ml}$ antiGRP78 antibody (clone ET-21; Sigma) or with unrelated control (rabbit IgG; Sigma) at the same concentration. As secondary antibody, peroxidase-coupled goat anti-rabbit IgG (Acris) was used.

Apoptosis Assay with SAM-6 on Transfected Tumor Cells The extent of antibody-induced apoptosis on BXPC-3 cells, before and after transfection with GRP78 siRNA, was detected by the Cell Death Detection ELISA ${ }^{\text {PLUS }}$ kit (Roche, Mannheim, Germany) according to the manufacturer's protocol. Forty-eight hours after transfection, $1 \times 10^{4}$ cells were plated on 96-well plates and incubated in the presence of $100 \mu \mathrm{g} / \mathrm{ml}$ SAM-6 antibody or unrelated IgM control (Chrompure human IgM, Dianova) for $4 \mathrm{~h}$ at $37^{\circ} \mathrm{C}$ under $7 \%$ $\mathrm{CO}_{2}$ in a humidified atmosphere. To demonstrate normal growth, cells were supplemented with complete growth medium.

\section{RNA Isolation and Semi-quantitative RT-PCR}

Total RNA from normal and cancerous gastric tissue was isolated using the phenol-guanidine-isothiocyanate method with TRIzol reagent (Invitrogen) as published elsewhere. ${ }^{26}$ mRNA levels of GRP78 in normal and cancerous gastric tissue were compared using semi-quantitative RT-PCR. Synthesis of first-strand cDNA was performed using standard protocols. A $5-\mu \mathrm{g}$ weight of isolated total RNA was reverse transcribed in the presence of oligo-deoxythymidylic acid primer and Super Script ${ }^{\mathrm{TM}}$ II Reverse Transcriptase (M-MLV $\mathrm{RT}$; Invitrogen $\mathrm{GmbH}$, Karlsruhe, Germany). Levels of GRP78 and GAPDH mRNA were detected by subsequent PCR analysis. Amplification of cDNA template was carried out in the presence of $2 \mathrm{nM} \mathrm{MgCl} 2,0.2 \mathrm{pM}$ of each primer, $250 \mu \mathrm{m}$ each deoxynucleoside triphosphate and $1 \mathrm{U}$ of Taq polymerase (MBI Fermentas, St Leon-Rot, Germany) in a final reaction volume of $25 \mu \mathrm{l}$. Expression of GRP78 mRNA was normalized to GAPDH mRNA levels. The primers specific for GRP78 and GAPDH were designed on their reported sequences and commercially synthesized by MWG-Biotech (Ebersberg, Germany). The sequences of these oligonucleotides are $5^{\prime}$-CAGGGGTCTTTCACCTTCATAG-3' (lower primer) and $5^{\prime}$-GTCATGGAACACTTCATCAAAC-3' (upper primer) for GRP78, and 5'-AGATGATGACCCTTTTGGCTC$3^{\prime}$ (lower primer) and 5'-AAGGTCGGAGTCAACGGATTT- $3^{\prime}$ (upper primer) for GAPDH. Sizes of expected amplification products are $610 \mathrm{bp}$ for GRP78 and $380 \mathrm{bp}$ for GAPDH. GRP78 was amplified at $94^{\circ} \mathrm{C}$ for $4 \mathrm{~min}$ and for 40 cycles at $94^{\circ} \mathrm{C}(30 \mathrm{~s}), 56.6^{\circ} \mathrm{C}(30 \mathrm{~s})$ and $72^{\circ} \mathrm{C}(30 \mathrm{~s})$, with a final extension step at $72^{\circ} \mathrm{C}(4 \mathrm{~min})$. As negative control, each PCR run included a sample containing PCR buffer but no cDNA. The PCR products were identified by agarose-gel electrophoresis in tris-acetate-EDTA buffer and ethidium bromide staining.

\section{Glycosidase Assay on Cytospins}

A total of $4 \times 10^{5}$ human pancreas carcinoma cells (BXPC-3) were resuspended in $1 \mathrm{ml}$ Dulbecco's phosphate-buffered 
saline (PBS), pH 7.2 (Sigma), and incubated with $5 \mathrm{U} / \mathrm{ml}$ $\mathrm{N}$-glycosidase or $20 \mathrm{mU} / \mathrm{ml} \mathrm{O}$-glycosidase (both from Roche Applied Science, Mannheim, Germany) for $4 \mathrm{~h}$ at $37^{\circ} \mathrm{C}$. Untreated cells in PBS served as control. Cytospins were prepared and immunohistochemical staining with antibody SAM-6 $(50 \mu \mathrm{g} / \mathrm{ml})$ or control antibodies was performed as described previously. ${ }^{22}$ Unrelated human IgM at the same concentration served as negative control (ChromPure human IgM; Dianova) and as positive controls, human anti-GRP78 $(50 \mu \mathrm{g} / \mathrm{ml}$, clone ET-21; Sigma) and human anti-CD55 antibody (1:30, clone 143-30; DPC Biermann) were used.

\section{Glycosidase Assay on Tumor Cell Membrane Extracts}

Membrane extract of the pancreas carcinoma cell line BXPC3 was prepared as described above. After adding SDS and $\beta$-mercaptoethanol (each in a final concentration of $1 \%$ ), the extract was denatured for $3 \mathrm{~min}$ at $95^{\circ} \mathrm{C}$ and finally diluted with reaction buffer (PBS, pH 7.4, 1\% Nonidet P-40, $1 \%$ $\beta$-mercaptoethanol) to a protein concentration of $0.5 \mathrm{mg} / \mathrm{ml}$. For deglycosylation of $\mathrm{O}$ - and $\mathrm{N}$-linked carbohydrates, aliquots of $100 \mu \mathrm{l}$ were incubated either with $10 \mathrm{U} N$-glycosidase F (Roche Applied Science) or $5 \mathrm{mU} \mathrm{O}$-glycosidase (Roche Applied Science) at $37^{\circ} \mathrm{C}$ for overnight. Untreated extract in reaction buffer served as control. The extent of deglycosylation was analyzed by SDS-PAGE and western blotting.

\section{RESULTS}

\section{Immunohistochemistry}

The epitope defined by the human monoclonal antibody SAM-6 is specifically expressed on malignant tissue, but is absent on non-transformed tissue. This has been shown in a previous publication. ${ }^{24}$ To further confirm and illustrate the tumor-specific expression of the SAM-6 antigen, the immunohistochemistry study was enlarged on a broad panel of malignant and non-malignant tissues (Table 1). As shown in Figure 1a-c, antibody SAM-6 reacts only with tumor cells; tissues surrounding the malignant areas are not stained. To mark the difference between positive and negative binding, a SAM-6-negative tumor is shown in Figure 1d. In addition, on healthy tissues SAM-6 shows no staining (Figure 1e and f). Thus, it can be clearly stated that SAM-6 binds to an epitope specifically expressed on malignant tissue.

\section{Isolation and Identification of the SAM-6 Target}

Immunohistocemical and immunofluorescence studies have clearly demonstrated that antibody SAM- 6 binds to a molecule, which is exclusively expressed on the cell membrane of cancer cells. ${ }^{24,25}$ Preliminary experiments have shown that on western blots, with membrane preparations of cancer cells the SAM-6 antibody binds to a molecule with a molecular weight of $140 \mathrm{kDa} \cdot{ }^{24}$ However, mass spectrometric analysis revealed that this band was a contamination of nuclear cell components, which was incorporated by non-optimal membrane preparation (data not shown). To get better enrichment of membrane proteins and less contamination, a more precise
Table 1 Expression of SAM- 6 antigen on human malignant and non-malignant tissues

(a) Malignant tissue

\begin{tabular}{llc} 
Tested tissue & Carcinoma type & SAM-6 \pm \\
\hline Esophagus & Squamous cell & $8 /-$ \\
& Adeno (Barrett) & $4 /-$ \\
Stomach & Adeno (diffuse) & $6 / 2$ \\
& Adeno (intestinal) & $10 / 3$ \\
Colon & Adeno & $5 / 1$ \\
Pancreas & Adeno (ductal) & $18 /-$ \\
Lung & Adeno & $36 /-$ \\
& Squamous cell & $37 / 1$ \\
Breast & Invasive (ductal) & $11 /-$ \\
& Invasive (lobular) & $5 / 2$ \\
Ovary & Adeno & $11 /-$ \\
Cervix & Adeno & $11 / 3$ \\
& Squamous cell & $5 / 2$ \\
Uterus & Adeno & $6 / 3$ \\
Prostate & Adeno & $11 / 2$
\end{tabular}

(b) Non-malignant tissue

Tested tissue Cell type SAM-6+

$\begin{array}{llc}\text { Stomach } & \text { Glandular } & - \\ \text { Colon } & \text { Epithelial } & - \\ \text { Lung } & \text { Glandular } & - \\ \text { Esophagus } & \text { Epithelial } & - \\ \text { Pancreas } & \text { Glandular } & - \\ \text { Liver } & \text { Glandular } & - \\ \text { Kidney } & \text { Epithelial } & - \\ \text { Prostate } & \text { Glandular } & - \\ \text { Testis } & \text { Germinal } & - \\ \text { Breast } & \text { Glandular } & - \\ \text { Uterus } & \text { Epithelial } & - \\ \text { Ovary } & \text { Glandular } & - \\ \text { Small intestine } & \text { Epithelial } & - \\ \text { Bladder } & \text { Epithelial } & -\end{array}$

preparation method using M-PEK (Calbiochem) was used. This method guarantees sufficient enrichment of membrane proteins and requires no further sub-cellular fractionation.

On western blots with membrane preparations of tumor cell line 23132/87 and BXPC-3, the SAM-6 antibody binds to a membrane molecule with a relative molecular mass of $82 \mathrm{kDa}$. Representative for both cell lines, western blotting with membrane extract of cell line $23132 / 87$ is shown in 
H\&E

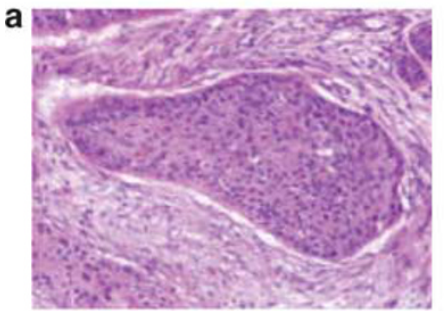

b
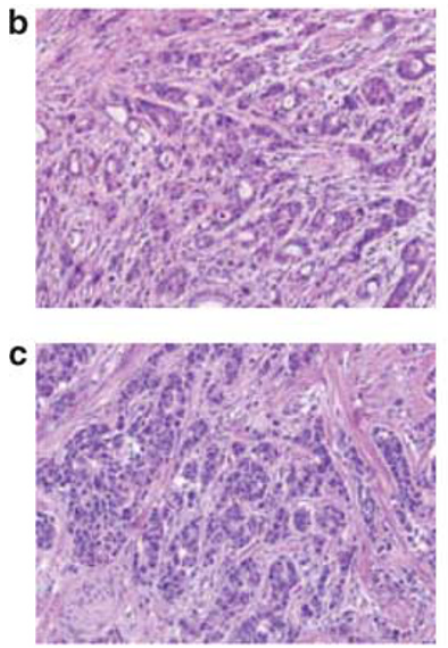

Anti-Keratin
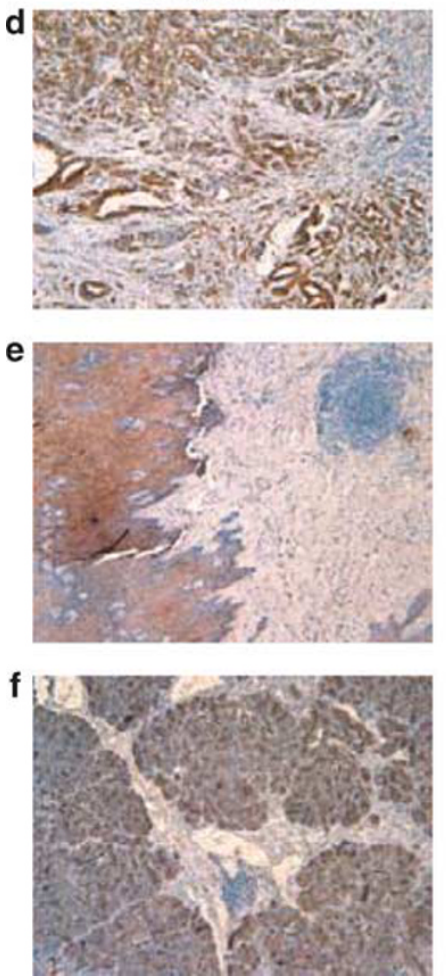

Isotype Control
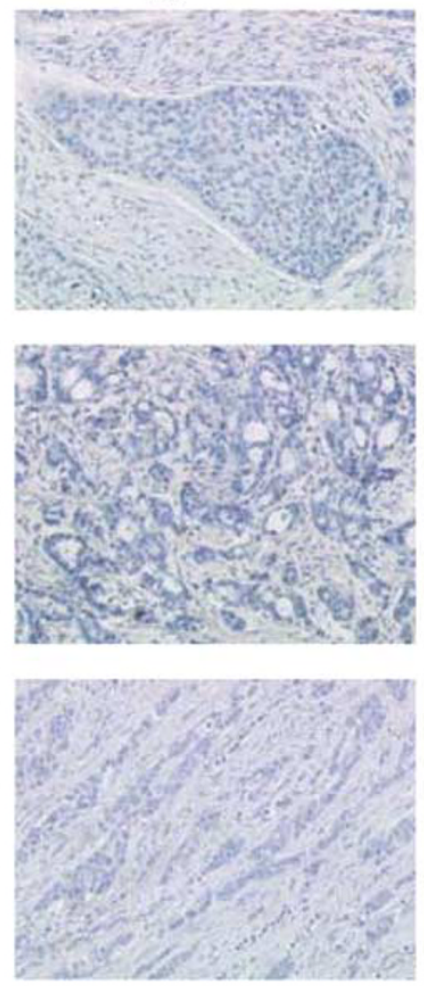

Isotype Control
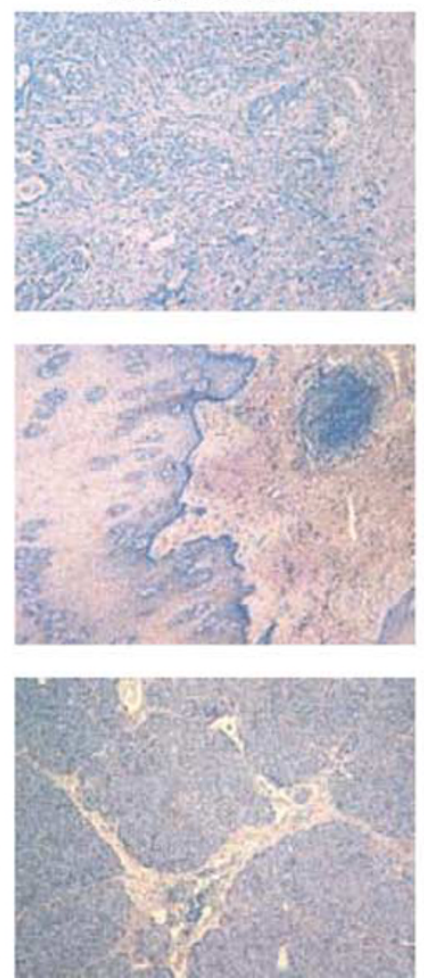

SAM-6
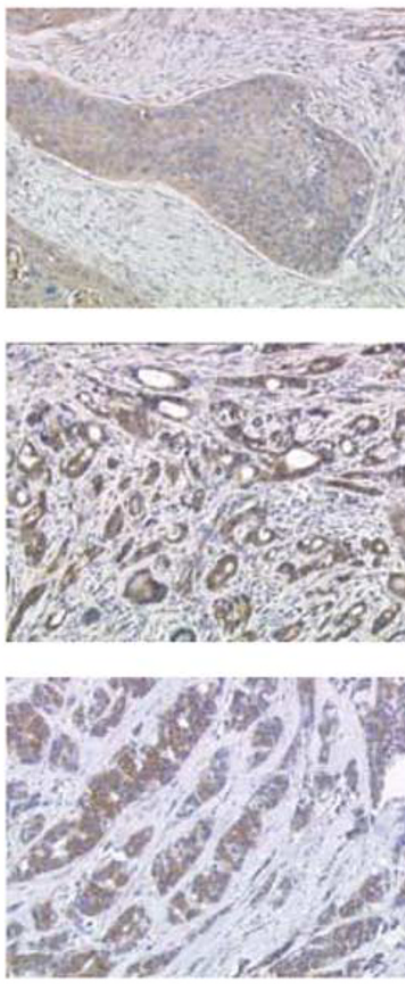

SAM-6
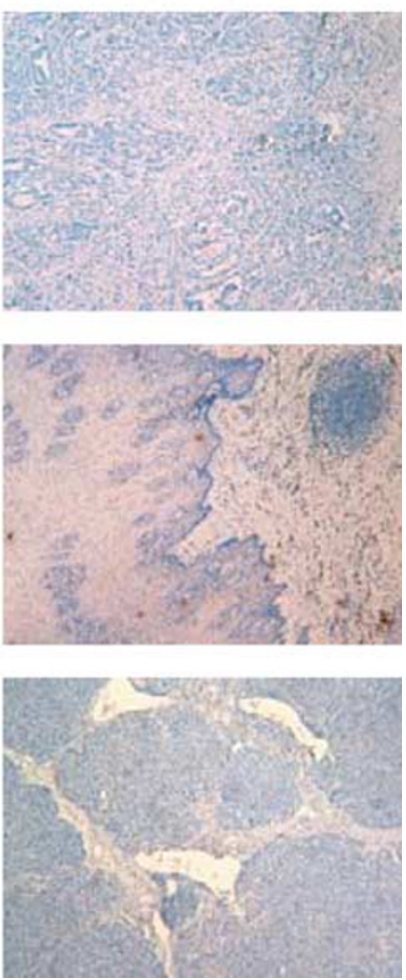

Figure 1 Immunohistochemical staining of antibody SAM-6 on different human carcinoma and normal tissues. Paraffin-embedded sections were incubated with antibody SAM- 6 or unrelated human isotype control as negative control. For morphological studies, tissues sections were stained with hematoxylineosin $(\mathbf{a}-\mathbf{c})$ or anti cytokeratin antibody respectively $(\mathbf{d}-\mathbf{f})$. (a) Esophageal squamous cell carcinoma. (b) Adenocarcinoma of the pancreas. (c) Invasive lobular carcinoma of the breast. (d) Adenocarcinoma of the stomach. (e) Normal esophageal tissue. (f) Normal pancreatic tissue. Antibody SAM-6 reacts specifically with malignant cells. 

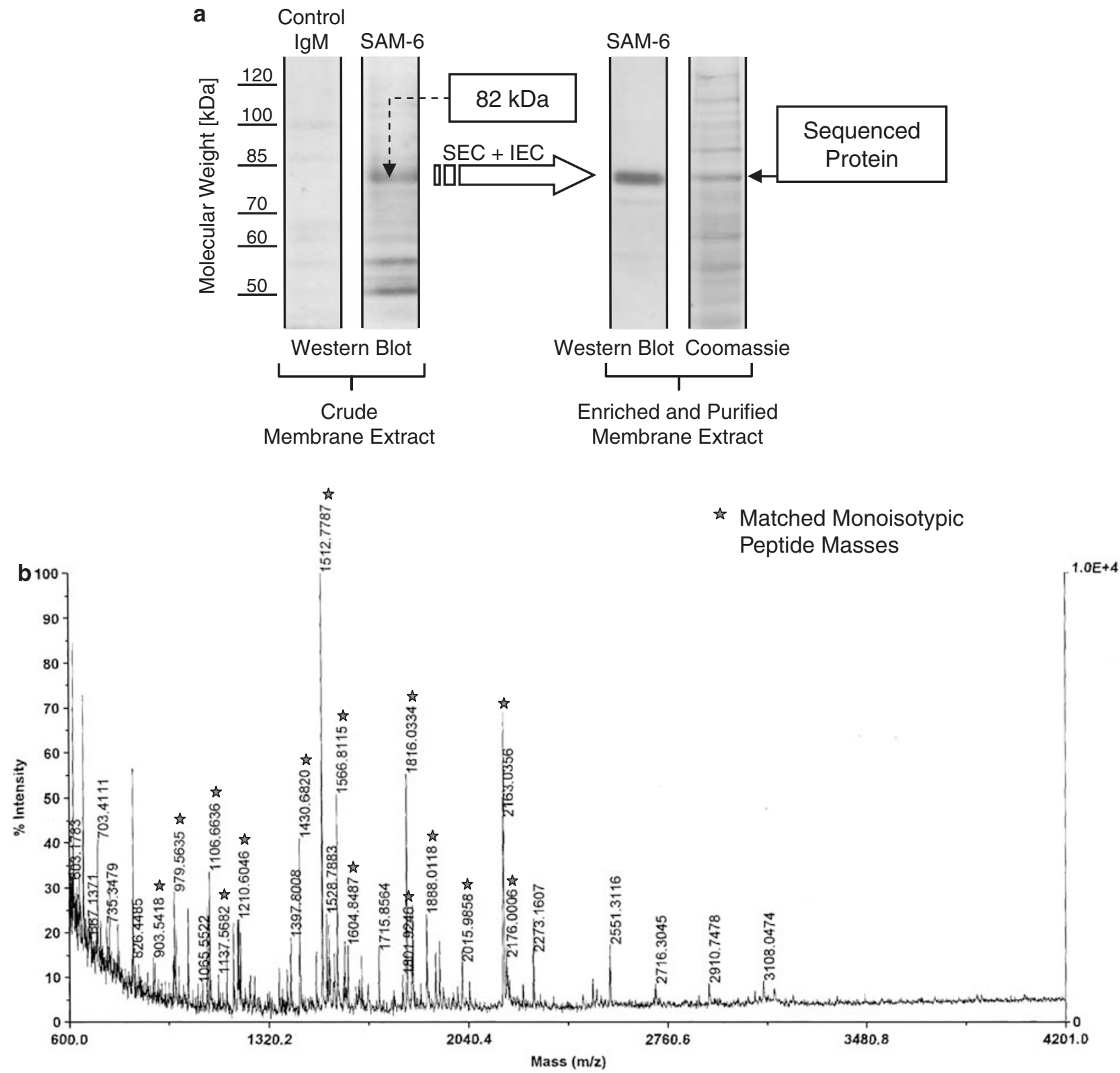

Figure 2 Identification of the antigen of antibody SAM- 6 by MALDI peptide mass mapping. Protein purification of the antigen from membrane extracts of stomach carcinoma cell line 23132/87. (a) Purified protein fraction after processing size-exclusion and ion-exchange chromatography with crude membrane extracts. Western blot analysis with control IgM and SAM-6 antibody. Western blot analysis with SAM- 6 antibody after the second purification step, and Coomassie staining of the same purified protein fraction. The protein band marked by the arrow was excised from Coomassie-stained gel and analyzed by MALDI mass spectroscopy (SEC, size-exclusion chromatography; IEC, ion-exchange chromatography). (b) Identification of the excised 82-kDa protein band by high-resolution MALDI peptide mass mapping. Peaks marked with asterisks ${ }^{*}$ ) matched the calculated masses of tryptic peptides of human GRP78 (accession number NP_005338.1) with a peptide mass error less than 50 p.p.m. The minimum sequence coverage of the corresponding amino acids was $35 \%$.

Figure 2a. Unspecific binding of IgM antibodies was controlled using unrelated human IgM.

For identification of the detected $82-\mathrm{kDa}$ protein, membrane extracts of cell line 23132/87 were enriched and purified by size-exclusion and successive anion-exchange chromatography. The protein band corresponding the SAM6 antigen (see Figure 2a) was finally excised from Coomassiestained gel and analyzed by MALDI mass spectroscopy.
Sequence database search with the matched set of tryptic peptide masses showed human GRP78 (accession number NP_005338.1) to be the highest-ranking candidate. A total of 21 tryptic peptide masses were assigned to GRP78 protein, corresponding to an amino-acid sequence coverage of minimum 35\%. The peptide mass error was less than 50 p.p.m. Matched peptide masses obtained by MALDI peptide-mass fingerprinting are indicated by asterisks in the 
peptide mass map (Figure $2 \mathrm{~b}$ ). Because of the high number of assigned peptides and the high sequence coverage, GRP78 protein could definitely be identified.

\section{Validation of GRP78 as SAM-6 Target}

To validate GRP78 as the SAM- 6 target, a transient knockdown experiment with siRNA was conducted that cleaves the GRP78 messenger RNA and blocks the protein expression on the cell surface.

The first experiment was performed to investigate the binding of SAM- 6 on tumor cells after silencing GRP78 gene expression. BXPC-3 tumor cells were transfected with siRNA targeting human GRP78. Positive binding of the antibodies on the control cells, representing day 0 of transfection, with $100 \%$ density of the expressed surface antigens, is shown (Figure 3a). To exclude nonspecific effects on gene expression caused by siRNA introduction, scrambled siRNA (Silencer Negative Control siRNA) was used as negative control. Figure 3a demonstrates that SAM-6 antibody shows a strong binding on cells treated with unrelated siRNA over the whole incubation period. The same results could be observed with the antibody recognizing surface-located GRP78. Likewise a strong binding could be observed with the anti-CD55 control, indicating that the silencing did not affect the expression of other cell surface membrane molecules.

On cells treated with siRNA against human GRP78 mRNA, FACS analysis with antibody specifically recognizing surfacelocated GRP78 showed decreased density of surface antigen accompanied with the downregulation of cell-surface GRP78 after three days (76\% reduction) (Figure 3a). Most interestingly, transfection of tumor cells with GRP78 siRNA also reduces target protein expression and binding of SAM-6 antibody (70\% reduction). The control with anti-CD55 shows again that silencing did not affect the expression of other surface membrane molecules (Figure 3a).

In addition, suppression of the target protein GRP78 was confirmed by western blotting on membrane extracts of transfected tumor cells. On membrane extracts of untreated tumor cells (BXPC-3), SAM-6 antibody binds to one specific protein band ( $82 \mathrm{kDa})$ (Figure $3 \mathrm{~b})$. Anti-GRP78 antibody, which recognizes an N-terminal peptide structure of GRP78, in addition, detects wild-type GRP78 $(78 \mathrm{kDa})$ and a degradation product $(72 \mathrm{kDa})$. On membrane extracts of GRP78-deficient tumor cells, both the antibodies show a clear decrease in their binding reaction. In contrast, on membrane extracts of cells transfected with unrelated control siRNA, unchanged binding of SAM-6 and anti-GRP78 antibody was detectable (Figure $3 \mathrm{~b}$ ).

Furthermore the apoptotic effect of SAM-6 antibody on tumor cells transfected with GRP78 siRNA was investigated using an apoptosis assay. Non-transfected cells and cells transfected with negative silencer or GRP78 siRNA, respectively, were incubated with SAM-6 antibody or unrelated IgM control antibody for $4 \mathrm{~h}$. Tumor-cell apoptosis was measured using Cell Death Detection ELISA. Figure 3c indicates that
SAM-6 antibody clearly induces apoptotic cell death of non-transfected cells and cells treated with negative silencer siRNA. In both cell lines the content of apoptotic cells was over $90 \%$, related to the amount of apoptotic cells grown in complete medium. In contrast, cells transfected with siRNA against GRP78, hence lacking of cell-surface GRP78, show a decreased content of apoptotic cells (15\%) after treatment with antibody SAM-6 (Figure 3c). This indicates that the surface expression of GRP78 is essential for the induction of SAM-6 apoptosis. Cell lines incubated with the IgM control antibody showed negligible apoptotic events smaller than $10 \%$ in all attempts.

\section{SAM-6-Specific Modification of GRP78 is Overexpressed on Tumor Tissue}

We stated that antibody SAM-6 reacts with an epitope on GRP78 found specifically on malignant cells. Therefore, the lack of SAM-6 binding to non-malignant cells can be either the result of non-expression of the antigen on normal cells, or of a post-transcriptional modification of GRP78, which is different to that found on normal cells. This was investigated at the molecular level. GRP78 mRNA of malignant and non-malignant human gastric tissue was examined using semi-quantitative RT-PCR (Figure 4). The RT-PCR method was standardized by using the constitutively expressed 'housekeeping gene' GAPDH as an internal control. The gene expression of GRP78 was clearly increased in gastric tumor tissue compared with non-malignant tissue.

The expression of cell-surface GRP78 on malignant cells was investigated on protein levels. After western blot analysis on membrane extracts of pancreas carcinoma cells (BXPC-3), SAM-6 showed a specific protein band $(82 \mathrm{kDa})$ (see Figure $3 \mathrm{~b})$. The anti-GRP78 antibody, which recognizes an Nterminal peptide structure of GRP78, in addition, detected wild-type GRP78 $(78 \mathrm{kDa})$ and a degradation product $(72 \mathrm{kDa})$ (see Figure $3 \mathrm{~b})$. Co-detection of the prominent $82-\mathrm{kDa}$ protein indicates the presence of a GRP78 isoform that carries additional modifications on its peptide backbone (ie, glycosylation, phosphorylation etc.). Due to differential binding pattern of both the antibodies, SAM- 6 and the commercial anti-GRP78 antibody presumably recognize different antigenic epitopes on GRP78. A SAM-6-specific isoform of cell-surface GRP78 (GRP78 ${ }^{\text {SAM-6 }}$ ) is coexpressed with wild-type GRP78.

\section{Carbo-epitope of SAM-6 on GRP78}

To determine whether $\mathrm{O}$ - or $\mathrm{N}$-linked sugar residues are involved in SAM-6 binding to tumor cells, cytospin preparations of BXPC-3 cancer cells were incubated with $\mathrm{N}$ - or $\mathrm{O}$-glycosidase. After treatment of the cells, binding of SAM-6 antibody and anti-GRP78 antibody was evaluated by immunohistochemical staining. In addition, an anti-CD55 antibody was used as positive control to demonstrate integrity of the cell membrane. Figure $5 \mathrm{a}$ shows a clear reduction of surface binding with SAM- 6 on cells treated 


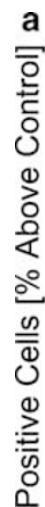

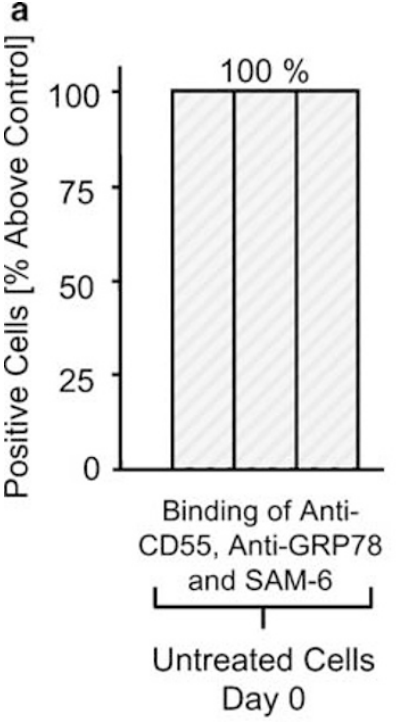

Time of Transfection: $\square$ Day 1

$\mathbb{N}$ Day 3

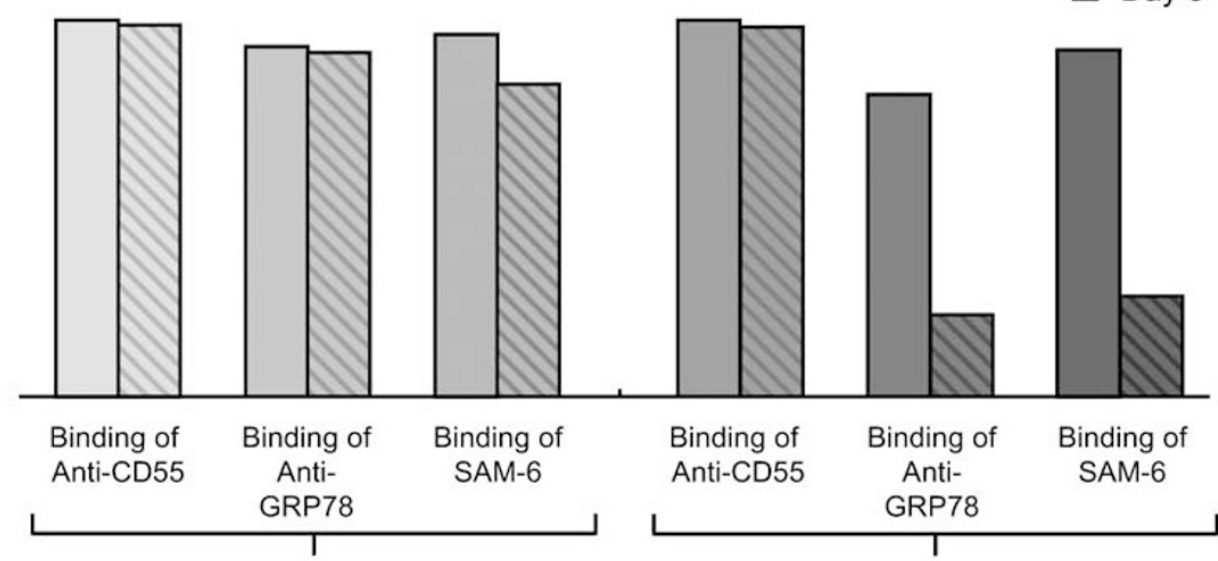

Cells Transfected with Negative Silencer ${ }^{T M}$ Cells Transfected with GRP78 siRNA SiRNA

b

A $\quad$ B $\quad$ C $M$

A

B C

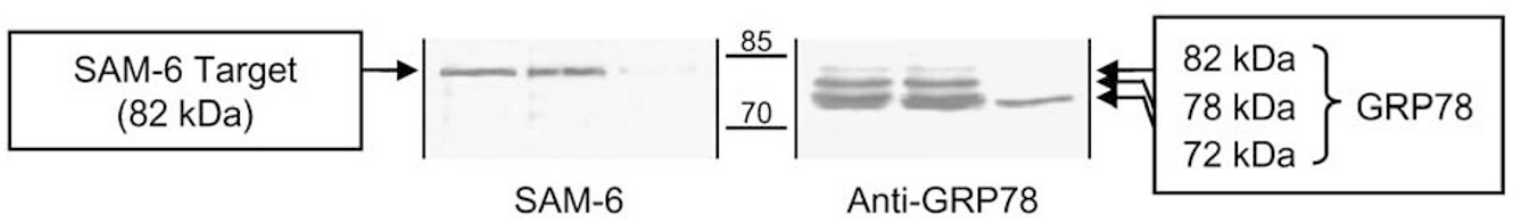

c

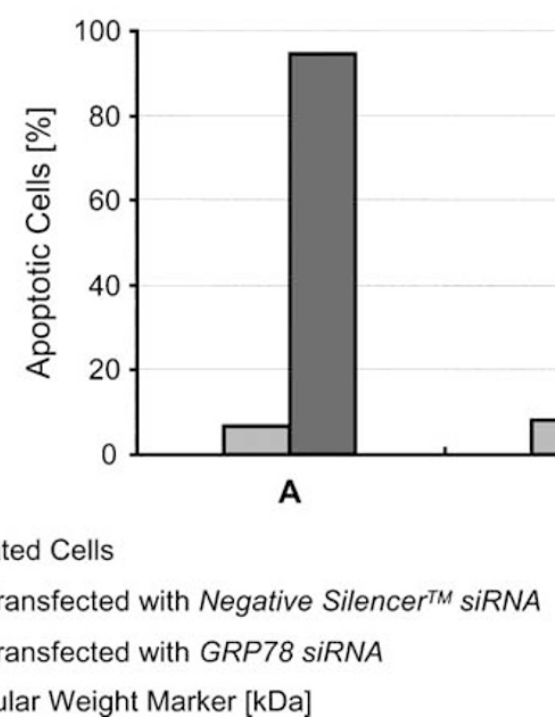

Figure 3 Validation of GRP78 as target for antibody SAM-6 by siRNA technology. Tumor cell line BXPC-3 was transfected with siRNA against human GRP78. (a) After 1 and 3 days, protein levels of GRP78 were monitored by FACS analysis. Percentages of cell-surface antigens of SAM- 6 and control antibodies are shown. Control cells show positive binding of anti-CD55, anti-GRP78 and SAM- 6 antibody on day 0 , corresponding to antigen density of $100 \%$. On cells transfected with Negative Silencer siRNA (unrelated siRNA), strong binding of SAM- 6 and control antibodies is detectable during the whole incubation time. Cells transfected with GRP78 siRNA show reduced binding of anti-GRP78 antibody (76\% reduction) and SAM-6 antibody (70\% reduction), but unchanged binding of anti-CD55 antibody at day 3. Knockdown of surface-located GRP78 reduces target protein expression and binding of SAM-6 antibody. (b) After

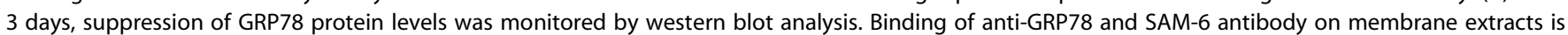
shown. SAM-6 binds to a specific protein band ( $82 \mathrm{kDa}$ ); anti-GRP78 antibody additionally detects wild-type GRP78 (78 kDa) and a degradation product of $72 \mathrm{kDa}$. On membrane extracts of cells transfected with GRP78 siRNA, binding of both antibodies is clearly decreased. In contrast, both antibodies show strong binding on membrane extracts of both untreated and control cells. (c) To demonstrate the extent of antibody-induced apoptosis of transfected tumor cells, an apoptosis assay (Cell Death Detection ELISA) was conducted. Transfected cells were incubated with $100 \mu \mathrm{g} / \mathrm{ml}$ of SAM- 6 antibody for $4 \mathrm{~h}$. Unrelated human IgM at the same concentration served as negative control. Tumor cells transfected with siRNA against human GRP78 show a clear reduction of the apoptotic activity induced by SAM- 6 antibody, compared with untreated cells and cells transfected with unrelated siRNA. Calculation of apoptotic cell content was related to the content of cells grown in complete medium. 


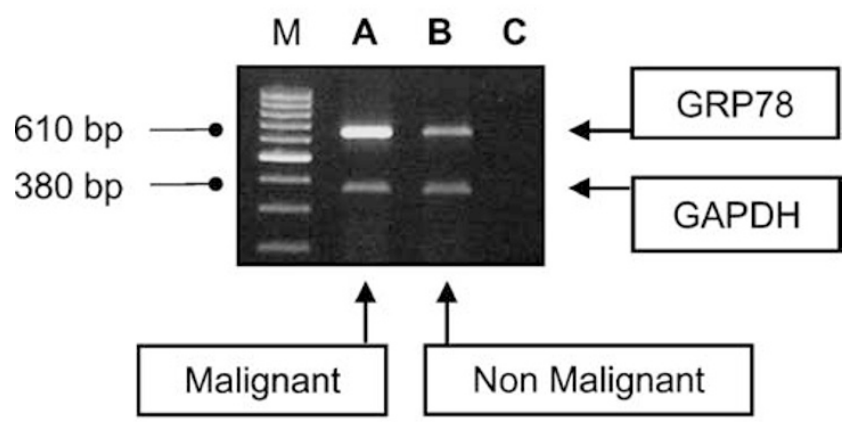

\section{A. Gastric Tumor Tissue \\ B. Non Malignat Gastric Tissue \\ C. Negative Control \\ M. 100 bp DNA Ladder}

Figure 4 Expression of GRP78 $8^{\mathrm{SAM}-6}$ on tumor membrane extracts. GRP78 mRNA level of malignant and non-malignant human gastric tissue was examined using semi-quantitative RT-PCR. The expression of GRP78 mRNA was normalized to GAPDH mRNA levels. Compared with non-malignant tissue, GRP78 mRNA is clearly overexpressed in tumor tissue.

with $\mathrm{O}$-glycosidase, whereas treatment with $\mathrm{N}$-glycosidase has no effect on SAM-6 binding. In contrast, treatment with $\mathrm{O}$ - and $\mathrm{N}$-glycosidase does not affect binding of the anti-GRP78 antibody to the cells.

To confirm these findings, the effect of deglycosylation was investigated on membrane extracts of the tumor cell line BXPC-3. Membrane extracts were deglycosylated with $\mathrm{O}$ - and $\mathrm{N}$-glycosidase and analyzed by western blotting. After the cleavage of $\mathrm{N}$-linked carbohydrates, the binding activity of SAM-6 is not influenced, but interestingly the treatment caused a reduction of the molecular weight of the target protein from 82 to $72 \mathrm{kDa}$. This indicates that $N$-linked carbohydrates are not involved in SAM-6 binding. In contrast, after digestion of the target protein with $O$-glycosidases, western blot analysis with antibody SAM-6 showed no detectable protein band (Figure $5 \mathrm{~b}$ ). To prove that the absence of SAM-6 binding after $\mathrm{O}$-glycosidase treatment is not due to an unspecific contaminated protease activity, we have also stained both $\mathrm{N}$ - and $\mathrm{O}$-treated samples with anti-GRP78 antibody. Figure 5b clearly shows that the anti-GRP78 antibody still binds to the $72-$ and $78-\mathrm{kDa}$ proteins. These results show that glycosidases have no protease activity and that the epitope of the SAM-6 antibody is an O-linked carbohydrate moiety.

\section{DISCUSSION}

In this study, we showed that the target defined by the human monoclonal IgM antibody SAM-6 is a new isoform of GRP78 $\left(\right.$ GRP78 ${ }^{\text {SAM-6 }}$ ), a member of the HSP70 family. The membrane-bound variant of GRP78 has a molecular weight of $82 \mathrm{kDa}$ and is specifically overexpressed in a wide range of cancer types, but is absent from normal tissue. GRP78 ${ }^{\mathrm{SAM}-6}$ is coexpressed with wild-type GRP78, which has a molecular weight of $78 \mathrm{kDa}$, and was recently found on the surface of certain cell types. ${ }^{19,20,27-31}$ The SAM-6-specific variant of GRP78 is post-transcriptionally modified and the epitope is a carbohydrate structure, which is specific for the plasma membrane molecule, but is not present on the intracellular GRP78 molecules.

Interestingly, the SAM-6 antigen on malignant cells is a chaperone that normally enables the cancer cell survival by reducing several kinds of cellular stress. ${ }^{3,7,32}$ The $78-\mathrm{kDa}$ GRP (GRP78) is also known as immunoglobulin heavy-chainbinding protein. Parts of synthesized GRP78 are found translocated to the cell surface, where it is involved in MHC class I antigen presentation, ${ }^{31}$ acts as co-receptor for ligands as viruses, ${ }^{33,34}$ serves as receptor for the angiogenesis inhibitor kringle $5^{19}$ or for activated forms of plasma proteinase inhibitor $\alpha 2$-macroglobulin $\left(\alpha_{2} \mathrm{M}^{*}\right)$. Binding of $\alpha 2$-macroglobulin to plasma membrane associated GRP78 induces mitogenic signaling, proliferation and increases metastatic potential. It activates a subsequent mechanism to promote cellular proliferation and blocks programmed cell death. ${ }^{29,30}$

Malignant cells are permanently exposed to stress, mainly induced by hypoxic conditions and glucose deprivation caused by poor vascularization in their metabolic microenvironment, ${ }^{35,36}$ and to immunological attacks. ${ }^{37,38}$ For their survival, they have to adapt their cellular turnover to a higher need of nutrition and energy. ${ }^{39}$ The natural induction of HSPs and activation of the UPR response in tumor tissues is therefore not surprising. They express high levels of HSPs to prevent cellular and molecular damage and to prolong survival. ${ }^{32,35,36}$ High levels of cell-surface-located GRP78 are found in and on a variety of carcinoma cells, such as breast cancer, ${ }^{15-17}$ lung cancer, ${ }^{40,41}$ gastric, ${ }^{11,42}$ hepatocellular ${ }^{43,44}$ and prostate cancers. ${ }^{18,45}$ Histological examination of human prostate cancers demonstrated that GRP78 is clearly upregulated both intracellular and on the cell surface of aggressive tumors. ${ }^{5,41}$ Overexpression of this chaperone obviously implicates higher drug resistance and a greater degree of malignancy, and is often associated with bad prognosis as reported in cases of breast, ${ }^{14,17}$ prostate $^{5}$ and gastric cancer. ${ }^{11}$ Zhang et al. showed that levels of GRP78 expression in gastric primary tumors or metastatic lymph nodes correlate inversely with patient survival. Another interesting aspect, which is also correlated with poor prognosis, is that in serum of prostate cancer patients natural antibodies to GRP78 were found, which clearly indicates the antigenic property of surface GRP78. ${ }^{46,47}$

Indeed, the expression of surface-located GRP78 on tumor cells may serve as biomarker for tumor behavior or treatment response, ${ }^{48}$ and may present GRP78 as an attractive target toward cancer cells. But, mechanisms of drug resistance induced by stress-response proteins like GRP78 are still unexplored and limit the effect of known chemotherapies. Combination therapy targeting GRP78 expression may represent a novel approach toward eradication of residual 
a

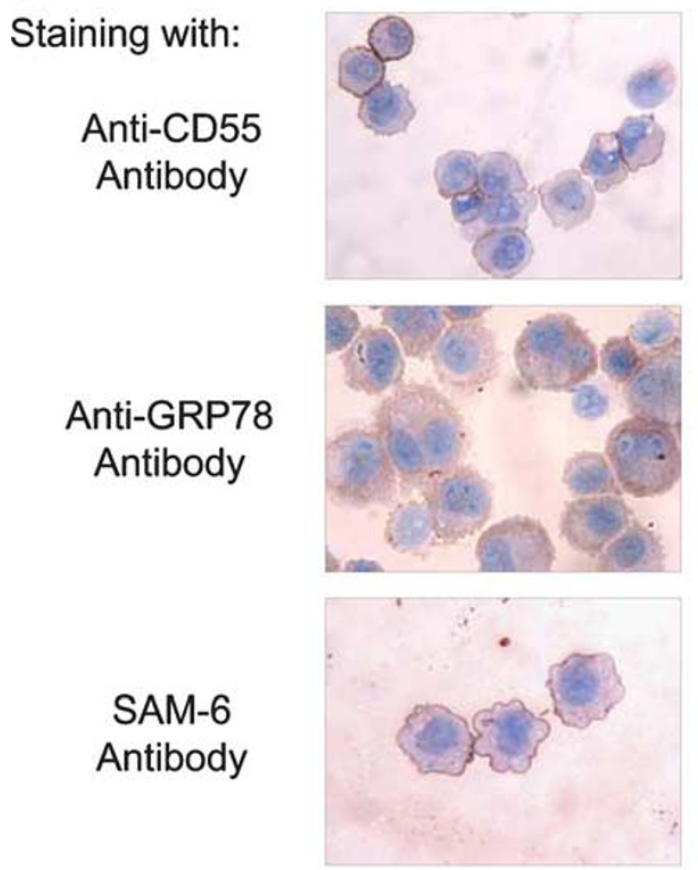

O-Glycosidase
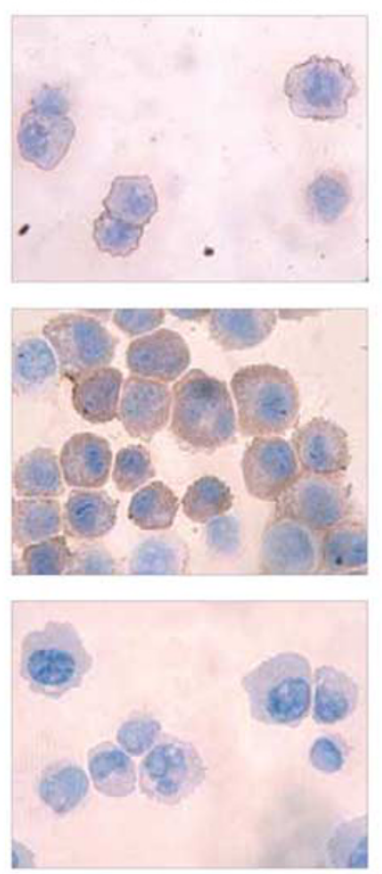

N-Glycosidase
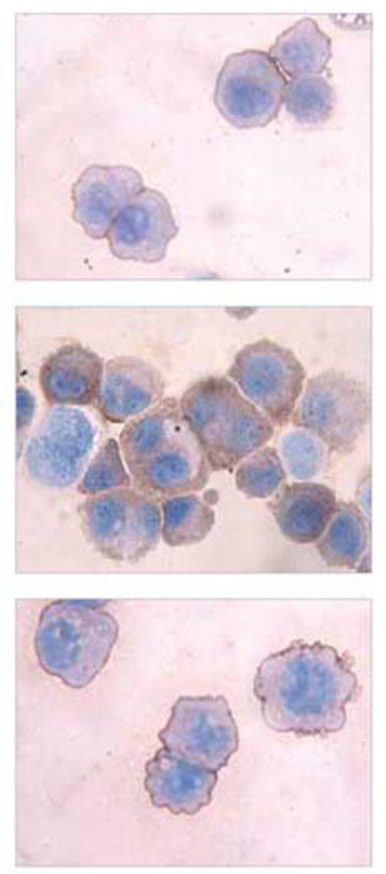

b
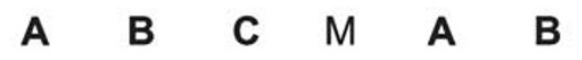

\section{SAM- 6 Target $(82 \mathrm{kDa})$}

\section{A. Untreated Cells \\ B. Cells treated with O-Glycosidase \\ C. Cells treated with N-Glycosidase \\ M. Molecular Weight Marker [kDa]}

Figure 5 Effect of $O$ - and $N$-deglycosylation on antibody SAM- 6 binding activity detected by immunohistochemistry and western blotting. (a) Cytospins of pancreas carcinoma cells (BXPC-3) after treatment with $\mathrm{N}$ - or O-glycosidase and immunohistochemical analysis with SAM-6 antibody, anti-GRP78 antibody or anti-CD55 antibody as control. Cells show no binding of SAM- 6 antibody after cleavage of O-linked carbohydrates. On untreated cells and on cells treated with $\mathrm{N}$-glycosidase, normal binding of SAM- 6 is visible. Treatment with $\mathrm{O}$ - and $\mathrm{N}$-glycosidases does not affect binding of anti-GRP78 antibody to the tumor cells. Binding of anti-CD55 antibody indicates integrity of the membrane after treatment with glycosidases. (b) Western blotting on membrane extracts of pancreas carcinoma cells (BXPC-3) after digestion with $O$ - and $N$-glycosidase. SAM- 6 shows no binding activity after $O$-deglycosylation of the target protein. Cleavage of $N$-linked carbohydrates reduces the molecular weight of the target, but shows no influence in binding of SAM-6 antibody. After treatment with $\mathrm{O}$ - and $\mathrm{N}$-glycosidase, anti-GRP78 antibody detects wild-type GRP78 $(78 \mathrm{kDa})$ and a degradation product of $72 \mathrm{kDa}$, but not the SAM-6 specific isoform $(82 \mathrm{kDa})$.

tumors. Several naturally occurring compounds with putative anticancer activity are said to inhibit either GRP78 expression or its activity at pharmacologic concentrations. This includes genistein, an active ingredient of soy, (-)epigallocatechin gallate, a green tea component, or salicylic acid from plants. ${ }^{48}$ But all these components act on many cellular and intracellular targets and pathways in addition to GRP78.

Additionally, GRP78 is also described on the surface of non-tumor cells such as fibroblasts macrophages and proliferating endothelium cells. ${ }^{19,20,49}$ Beside its negative implicated role in cancer, surface GRP78 shows even protective functions in the progression of atherothrombotic and cardiovascular diseases, ${ }^{20}$ and antiapoptotic properties as to proliferating endothelial cells, ${ }^{19}$ thus limiting its application because of expectant negative side effects.

We showed that SAM-6 binds to an $O$-linked carbohydrate moiety expressed on a membrane-bound isoform of GRP78. Cancer-associated changes in glycosylation include both the under- and overexpression of naturally occurring glycans, as well as neo-expression of glycans. ${ }^{50}$ These 'tumor-associated carbohydrate antigens' are prominent targets of immune 
surveillance and natural IgM antibodies. ${ }^{22,23}$ For example, the human antibody SC-1 detects a new isoform of the complement protection molecule CD55 on stomach cancer cells, ${ }^{51,52}$ and the human antibody PAM-1 binds to a new variant of the growth factor receptor, CFR- $1 .{ }^{26,53}$ Recently, a variant of GRP94, modified in its carbohydrate structure, was detected in more aggressive cancer prostate tissues but not normal tissues. ${ }^{54}$ The modifications are in all cases found in the carbohydrate structure of the molecule and in part, are coexpressed with their wild types on the tumor cell surface. This is not surprising because malignant cells often modify their carbo-pattern by post-transcriptional activity in adaption to their elevated and new needs of growth factors, protection factors, adhesion molecules etc. ${ }^{55,56}$

The glycosylation of wild-type GRP78 has not been widely studied. Major changes in ganglioside or glycoprotein expression and composition are post-transcriptional modifications that occur on serine or threonine residues (O-linked) or asparagines residues ( $\mathrm{N}$-linked), and concretely associate with oncogenic transformation. ${ }^{55,56}$ Hereby, glycosyltransferases, which are known to be overexpressed by tumor cells, promote alterations in the cellular glycosylation pattern of specific proteins, which end in malignant transformations of the cells. Significantly, these changes were found to occur in a wide range of carcinomas and to be correlated with tumor progression, metastasis, and patient survival rate. ${ }^{56}$

In previous studies, we demonstrated that malignant cells treated with SAM-6 antibody over-accumulate lethal depots of cholesterol and triglyceride esters. ${ }^{24,25}$ The deadly effect of SAM-6 can be increased after addition of oxidized LDL (oxLDL). ${ }^{25}$ This non-physiological lipid accumulation was shown to be tumor specific and always resulted in tumorspecific apoptosis or lipoptosis. ${ }^{24,25}$

The exact mechanism of SAM-6 activity is not known, but is under investigation. It is known that the antibody binds oxLDL and modifies GRP78. Subsequently, it is internalized via endocytosis and finally is responsible for accumulation of lipid depots. ${ }^{25,57}$ This induces a deadly cascade, starting with cytochrome $c$ release from mitochondria and caspase activation. ${ }^{25}$ We do not know how this oxLDL/antibody/receptor complex induces lipotoxicity in cancer cells. It is possible that SAM-6 binds similar epitopes on GRP78 and oxLDL, and over-feeds the cancer cells by receptor-mediated endocytosis. It is also possible that SAM-6 binding to GRP78 inactivates the protector function of the molecule, thus leading to an uncontrolled lipid uptake.

Recently, internalization of cell-surface-resident GRP78 after binding of peptidic ligands was reported. ${ }^{58}$ Others found that members of the HSP70 family (including GRP78) on mammalian cells interact with scavenger molecules, which are responsible for the uptake of oxLDL, and lead to a rapid internalization of HSP70 antigens. ${ }^{59}$ GRP78 is highly involved in the quality control of LDL receptors, and it associates with apolipoprotein B as part of a complex with other chaperones like GRP94, calreticulin and Erp72. ${ }^{60}$
Post-transcriptional modifications like glycosylations can modulate the interactions of HSP70 proteins with LDLbinding molecules. Furthermore, HSP70 molecules compete with oxLDL for binding to scavenger receptors, which indicates that both molecules have overlapping regions. ${ }^{60}$ It is therefore not surprising that a human antibody like SAM-6 binds to both GRP78 and oxLDL. And it is likely that this specific cross-reactivity is the reason for the uncontrolled uptake of oxLDL and the lipoptotic cell death.

Our results confirm the potential of human monoclonal antibodies isolated directly from humans for defining new tumor-specific killing mechanisms and new tumor-specific structures. They also show that cancer cells are sensitive to immunological weapons directed against structures they need for survival, namely protection molecules. Ironically, this molecular protection is important for survival of the malignant cell and is also responsible for bad prognosis, but makes the cell sensitive to immunological attack. The recent discovery of the SAM-6-specific variant of GRP78 on cancer cells offers the promise of a more precise therapy against cancer via the modified SAM-6-specific variant of surfacelocated GRP78, and opens a new door in antibody-targeted therapy.

\section{ACKNOWLEDGEMENT}

We thank Mrs Annette Vollmers for improving the manuscript.

1. Kiang JG, Tsokos GC. Heat shock protein $70 \mathrm{kDa}$ : molecular biology, biochemistry, and physiology. Pharmacol Ther 1998;80:183-201.

2. Hendershot LM. The ER chaperone BiP is a master regulator of ER function. Mt Sinai J Med 2004;71:289-297.

3. Ma $Y$, Hendershot LM. The role of the unfolded protein response in tumour development: friend or foe? Nat Rev Cancer 2004;4:966-977.

4. Lee AS. The glucose-regulated proteins: stress induction and clinical applications. Trends Biochem Sci 2001;26:504-510.

5. Daneshmand S, Quek ML, Lin E, et al. Glucose-regulated protein GRP78 is upregulated in prostate cancer and correlates with recurrence and survival. Hum Pathol 2007;38:1547-1552.

6. Kondo $Y$, Kanzawa $T$, Sawaya $R$, et al. The role of autophagy in cancer development and response to therapy. Nat Rev Cancer 2005;5: 726-734.

7. Ni M, Lee AS. ER chaperones in mammalian development and human diseases. FEBS Lett 2007;581:3641-3651.

8. Cabanes D, Sousa S, Cebria A, et al. Gp96 is a receptor for a novel Listeria monocytogenes virulence factor, Vip, a surface protein. EMBO J 2005;24:2827-2838.

9. Misra UK, Gonzalez-Gronow M, Gawdi G, et al. A novel receptor function for the heat shock protein Grp78: silencing of Grp78 gene expression attenuates alpha $2 \mathrm{M}^{*}$-induced signalling. Cell Signal 2004;16:929-938.

10. Jamora C, Dennert G, Lee AS. Inhibition of tumor progression by suppression of stress protein GRP78/BiP induction in fibrosarcoma B/C10ME. Proc Natl Acad Sci USA 1996;93:7690-7694.

11. Zhang J, Jiang Y, Jia Z, et al. Association of elevated GRP78 expression with increased lymph node metastasis and poor prognosis in patients with gastric cancer. Clin Exp Metastasis 2006;23:401-410.

12. Wang $Q$, Wang $T$, Wang $Y$, et al. VP-16 resistance in the $\mathrm{NCl}-\mathrm{H} 460$ human lung cancer cell line is significantly associated with glucoseregulated protein78 (GRP78) induction. Anticancer Res $2007 ; 27$ : 2359-2364.

13. Tsutsumi $\mathrm{S}$, Namba $\mathrm{T}$, Tanaka Kl, et al. Celecoxib upregulates endoplasmic reticulum chaperones that inhibit celecoxib-induced apoptosis in human gastric cells. Oncogene 2006;25:1018-1029. 
14. Dong $\mathrm{D}, \mathrm{Ko} \mathrm{B}$, Baumeister $\mathrm{P}$, et al. Vascular targeting and antiangiogenesis agents induce drug resistance effector GRP78 within the tumor microenvironment. Cancer Res 2005;65:5785-5791.

15. Fernandez PM, Tabbara SO, Jacobs LK, et al. Overexpression of the glucose-regulated stress gene GRP78 in malignant but not benign human breast lesions. Breast Cancer Res Treat 2000;59:15-26.

16. Gazit G, Lu J, Lee AS. Deregulation of GRP stress protein expression in human breast cancer cell lines. Breast Cancer Res Treat 1999;54: 135-146.

17. Lee E, Nichols P, Spicer D, et al. GRP78 as a novel predictor of responsiveness to chemotherapy in breast cancer. Cancer Res 2006;66:7849-7853.

18. Pootrakul L, Datar RH, Shi SR, et al. Expression of stress response protein Grp78 is associated with the development of castrationresistant prostate cancer. Clin Cancer Res 2006;12:5987-5993.

19. Davidson DJ, Haskell C, Majest $S$, et al. Kringle 5 of human plasminogen induces apoptosis of endothelial and tumor cells through surface-expressed glucose-regulated protein 78. Cancer Res 2005;65:4663-4672.

20. Bhattacharjee G, Ahamed J, Pedersen B, et al. Regulation of tissue factor-mediated initiation of the coagulation cascade by cell surface grp78. Arterioscler Thromb Vasc Biol 2005;25:1737-1743.

21. Dennis JW, Granovsky M, Warren CE. Glycoprotein glycosylation and cancer progression. Biochim Biophys Acta 1999;1473:21-34.

22. Brandlein S, Pohle T, Ruoff N, et al. Natural IgM antibodies and immunosurveillance mechanisms against epithelial cancer cells in humans. Cancer Res 2003;63:7995-8005.

23. Hensel F, Knorr C, Hermann R, et al. Mitogenic autoantibodies in Helicobacter pylori-associated stomach cancerogenesis. Int J Cancer 1999;81:229-235.

24. Pohle T, Brandlein S, Ruoff N, et al. Lipoptosis: tumor-specific cell death by antibody-induced intracellular lipid accumulation. Cancer Res 2004;64:3900-3906.

25. Brandlein S, Rauschert N, Rasche $L$, et al. The human $\lg M$ antibody SAM-6 induces tumor-specific apoptosis with oxidized low-density lipoprotein. Mol Cancer Ther 2007;6:326-333.

26. Brandlein S, Beyer I, Eck $M$, et al. Cysteine-rich fibroblast growth factor receptor 1, a new marker for precancerous epithelial lesions defined by the human monoclonal antibody PAM-1. Cancer Res 2003;63:2052-2061.

27. Delpino A, Piselli P, Vismara D, et al. Cell surface localization of the $78 \mathrm{kDa}$ glucose regulated protein (GRP 78) induced by thapsigargin. Mol Membr Biol 1998;15:21-26.

28. Fu Y, Lee AS. Glucose regulated proteins in cancer progression, drug resistance and immunotherapy. Cancer Biol Ther 2006;5:741-744.

29. Misra UK, Deedwania R, Pizzo SV. Activation and cross-talk between Akt, NF-kappaB, and unfolded protein response signaling in 1-LN prostate cancer cells consequent to ligation of cell surface-associated GRP78. J Biol Chem 2006;281:13694-13707.

30. Misra UK, Gonzalez-Gronow M, Gawdi G, et al. The role of MTJ-1 in cell surface translocation of GRP78, a receptor for alpha 2-macroglobulindependent signaling. J Immunol 2005;174:2092-2097.

31. Triantafilou M, Fradelizi D, Triantafilou K. Major histocompatibility class one molecule associates with glucose regulated protein (GRP) 78 on the cell surface. Hum Immunol 2001;62:764-770.

32. Li J, Lee AS. Stress induction of GRP78/BiP and its role in cancer. Curr Mol Med 2006;6:45-54.

33. Jindadamrongwech S, Thepparit C, Smith DR. Identification of GRP 78 (BiP) as a liver cell expressed receptor element for dengue virus serotype 2. Arch Virol 2004;149:915-927.

34. Triantafilou K, Fradelizi D, Wilson K, et al. GRP78, a coreceptor for coxsackievirus A9, interacts with major histocompatibility complex class I molecules which mediate virus internalization. J Virol 2002;76:633-643.

35. Feldman DE, Chauhan V, Koong AC. The unfolded protein response: a novel component of the hypoxic stress response in tumors. Mol Cancer Res 2005;3:597-605.

36. Koumenis C. ER stress, hypoxia tolerance and tumor progression. Curr Mol Med 2006;6:55-69.

37. Vollmers HP, Brandlein S. The 'early birds': natural IgM antibodies and immune surveillance. Histol Histopathol 2005;20:927-937.
38. Vollmers HP, Brandlein S. Death by stress: natural IgM-induced apoptosis. Methods Find Exp Clin Pharmacol 2005;27:185-191.

39. Gatenby RA. The potential role of transformation-induced metabolic changes in tumor-host interaction. Cancer Res 1995;55:4151-4156.

40. Koomagi R, Mattern J, Volm M. Glucose-related protein (GRP78) and its relationship to the drug-resistance proteins P170, GST-pi, LRP56 and angiogenesis in non-small cell lung carcinomas. Anticancer Res 1999;19:4333-4336.

41. Uramoto $\mathrm{H}$, Sugio $\mathrm{K}$, Oyama $\mathrm{T}$, et al. Expression of endoplasmic reticulum molecular chaperone Grp78 in human lung cancer and its clinical significance. Lung Cancer 2005;49:55-62.

42. Song MS, Park YK, Lee JH, et al. Induction of glucose-regulated protein 78 by chronic hypoxia in human gastric tumor cells through a protein kinase C-epsilon/ERK/AP-1 signaling cascade. Cancer Res 2001;61:8322-8330.

43. Lim SO, Park SG, Yoo JH, et al. Expression of heat shock proteins (HSP27, HSP60, HSP70, HSP90, GRP78, GRP94) in hepatitis B virusrelated hepatocellular carcinomas and dysplastic nodules. World J Gastroenterol 2005;11:2072-2079.

44. Shuda M, Kondoh N, Imazeki N, et al. Activation of the ATF6, XBP1 and grp78 genes in human hepatocellular carcinoma: a possible involvement of the ER stress pathway in hepatocarcinogenesis. J Hepatol 2003;38:605-614.

45. Misra UK, Gonzalez-Gronow M, Gawdi G, et al. The role of Grp 78 in alpha 2-macroglobulin-induced signal transduction. Evidence from RNA interference that the low density lipoprotein receptor-related protein is associated with, but not necessary for, GRP 78-mediated signal transduction. J Biol Chem 2002;277:42082-42087.

46. Arap MA, Lahdenranta J, Mintz PJ, et al. Cell surface expression of the stress response chaperone GRP78 enables tumor targeting by circulating ligands. Cancer Cell 2004;6:275-284.

47. Gonzalez-Gronow M, Cuchacovich M, Llanos C, et al. Prostate cancer cell proliferation in vitro is modulated by antibodies against glucoseregulated protein 78 isolated from patient serum. Cancer Res 2006;66:11424-11431.

48. Lee AS. GRP78 induction in cancer: therapeutic and prognostic implications. Cancer Res 2007;67:3496-3499.

49. Misra UK, Gonzalez-Gronow M, Gawdi G, et al. Up-regulation of the alpha2-macroglobulin signaling receptor on rheumatoid synovial fibroblasts. J Biol Chem 1997;272:497-502.

50. Dwek MV, Brooks SA. Harnessing changes in cellular glycosylation in new cancer treatment strategies. Curr Cancer Drug Targets 2004;4:425-442.

51. Hensel F, Hermann R, Brandlein $S$, et al. Regulation of the new coexpressed CD55 (decay-accelerating factor) receptor on stomach carcinoma cells involved in antibody SC-1-induced apoptosis. Lab Invest 2001;81:1553-1563.

52. Hensel F, Hermann R, Schubert $C$, et al. Characterization of glycosylphosphatidylinositol-linked molecule CD55/decay-accelerating factor as the receptor for antibody SC-1-induced apoptosis. Cancer Res 1999;59:5299-5306.

53. Hensel $F$, Brandlein $S$, Eck $M$, et al. A novel proliferation-associated variant of CFR-1 defined by a human monoclonal antibody. Lab Invest 2001;81:1097-1108.

54. Suriano R, Ghosh SK, Ashok BT, et al. Differences in glycosylation patterns of heat shock protein, gp96: implications for prostate cancer prevention. Cancer Res 2005;65:6466-6475.

55. Dube DH, Bertozzi CR. Glycans in cancer and inflammation-potential for therapeutics and diagnostics. Nat Rev Drug Discov 2005:4:477-488.

56. Fuster MM, Esko JD. The sweet and sour of cancer: glycans as novel therapeutic targets. Nat Rev Cancer 2005;5:526-542.

57. Vollmers HP, Brandlein S. Natural IgM antibodies: from parias to parvenus. Histol Histopathol 2006:21:1355-1366.

58. Liu Y, Steiniger SC, Kim Y, et al. Mechanistic studies of a peptidic GRP78 ligand for cancer cell-specific drug delivery. Mol Pharm 2007;4:435-447.

59. Theriault JR, Adachi H, Calderwood SK. Role of scavenger receptors in the binding and internalization of heat shock protein 70 . J Immunol 2006;177:8604-8611.

60. Sorensen S, Ranheim T, Bakken KS, et al. Retention of mutant low density lipoprotein receptor in endoplasmic reticulum (ER) leads to ER stress. J Biol Chem 2006;281:468-476. 